Published in Global Public Health - 2021

\title{
Barriers to care: the influence of gang violence on heterosexual men's initiation and adherence with the HIV/TB care cascade
}

Catherine Lima-Chantre ${ }^{\mathrm{a}}$, Janet Seeley ${ }^{\mathrm{b}}$ and Christopher Colvin ${ }^{\mathrm{a}, \mathrm{c}}$
a. Division of Social and Behavioural Sciences, Faculty of Health Sciences, University of Cape Town Cape Town, South Africa
b. Department of Global Health and Development, Faculty of Public Health and Policy, London School of Hygiene and Tropical Medicine, London, UK
c. Department of Public Health Sciences, University of Virginia, Charlottesville, VA, USA

\begin{abstract}
South Africa is burdened by twin epidemics of HIV and tuberculosis (TB) in which men are less likely than their female counterparts to engage with prevention, treatment and care. In some Cape Flats communities in Cape Town, South Africa, the challenge to men is compounded by high levels of gang violence. This study investigates the role of gang violence as a barrier to men's entry and retention in the HIV/TB care cascade. Data for this study drew from six weeks of participant observation and eleven in-depth interviews in Hanover Park, a largely Coloured township of Cape Town. Key findings concerned men's restricted mobility due to gang violence as a result of conflict over gang territory. Men both inside and outside gangs are affected by this violence, with men in gangs, in most cases, being totally cut off from healthcare services. Our findings show that men in gangs are a key risk population group for both HIV and TB programming. Community-based interventions that address the effects of violence on health services should be designed for the communities on the Cape Flats. Our findings could potentially be extrapolated to other settings affected by gang violence, both within South Africa and abroad.
\end{abstract}

Keywords: violence, gangs, access to care, HIV/TB care cascade, gender 


\section{Introduction \\ Background}

In the last decade, researchers have begun to focus on heterosexual men in HIV prevention programmes because of their decreased likelihood to be tested for HIV, initiate on ART after discovering their status, and remain adherent on treatment and virally suppressed (Cornell et al., 2011; Hensen et al., 2014; Mills et al., 2012). A gendered gap in care and treatment for tuberculosis also persists, with men being more likely to be infected with and to die from TB than women (Horton et al., 2016, 2018). South Africa is burdened by twin epidemics of HIV and tuberculosis (TB), with HIV/AIDS being the leading killer of South Africans (Pillay-van Wyk et al., 2016). Given the gender gap in the treatment and survival for the two conditions, a greater focus on men's engagement with HIV/TB care is vital to the prevention and control of the two epidemics within South Africa (Cornell et al. 2020; Makusha et al. 2020).

A wide variety of individual, community, and structural factors may prevent men from linking with care (Fleming et al., 2016; Siu et al., 2013, 2014). The role of violence in men's lives, as a barrier to access to care, has, however, been under-researched. Just with respect to mortality, South Africa's second National Disease Burden Study reveals interpersonal violence as the second leading cause of death for South African males, and resulting in an estimated $7.3 \%$ of years of life lost (Pillay-van Wyk et al., 2016).

A common source of interpersonal violence in South Africa is gang violence. Interpersonal violence is a defining feature of gangs and is embedded in their practice (Makanga et al., 2017). This violence is shaped by masculine gender norms performed by men in gangs, and is expressed in, for example, risky sex, gun violence, substance abuse, and sexual violence (SalasWright et al., 2015; Voisin et al., 2011; Walsh \& Mitchell, 2006). While men are the main perpetrators of gang violence, they are also its primary victims. However, there has been a tendency in public health and the public discourse more generally to see these men only as perpetrators or occasional victims of violence who need more aggressive policing.

The ways in which violence is produced and experienced in these men's environments are not often adequately understood. While the violence committed by gang members is rightfully criminalized, there is very little recognition of the significant social and economic challenges men in these settings face (Logie et al., 2017). It is important to interrogate the effects of criminalised spaces on men's HIV risk and access to critical health services in South Africa. Doing so could help us better understand how violence is produced in these areas while also discovering ways of more effectively intervening and addressing the role of violence in a variety of health problems, including HIV and TB.

In Cape Town, a city with one of the highest crime rates in South Africa, interpersonal violence-and specifically gang violence-plagues and often organises the social fabric of marginalised communities (Crime Stats SA, 2019.; Salo, 2003). Often referred to as "mixed, nonindigenous, populations of colour", communities classified as 'Coloured' in Cape Town have a complex history and marginalization rooted in South Africa's colonial and apartheid eras 
(Adhikari, 2009). The Coloured townships of the outskirts of Cape Town are, in particular, severely affected by poverty and gang violence (Salo, 2006).

In this paper, we investigate the role of gang violence in the Cape Town community of Hanover Park and the degree to which it impedes and shapes the ability of men in this township to engage with HIV/TB care.

\section{Methodology}

This ethnographic study took place in the community of Hanover Park, Cape Town in the Western Cape province of South Africa. The township has a population of around 32,000 inhabitants, nearly all of whom identify as 'Coloured', and is part of the Cape Flats, just outside the immediate Cape Town metro area. The prevalence of HIV and TB in Cape Town is estimated to be $5.2 \%$ and 885 per 100,000 cases respectively (Kanabus, 2020; Shisana et al., 2014).The crime rate in the Western Cape province is also high (Crime Stats SA, 2019). Shootings are a frequent occurrence in Hanover Park: the first author observed two shootings directly next to the local hospital during fieldwork in 2019.

The data collection occurred over a period of 6 weeks in 2019 during which the first author lived and conducted fieldwork in three neighbourhoods of the township. She conducted participant observation, documenting what was seen throughout the day and at night either around her residence, the vicinity of the hospital and clinic, or in other areas. She captured how many shootings occurred during the day, the demographic profile of both clinics, and the general climate of the area. Fieldnotes were written daily.

The 11 interviewees included in this study were selected through purposive sampling. Inclusion criteria for the study were being 18 years or older, a heterosexually-identified male who lived within Hanover Park, and being positive for either HIV and/or TB. These inclusion criteria were difficult to apply, particularly around the choice of "males" and "heterosexuals". Men were selected from the daily roster of patients attending an HIV/TB clinic at the local hospital.

None of the participants interviewed were active gang members (with only one being a selfidentified former gang member). Often staff, or wives and girlfriends of patients would complain of their partner who failed to attend appointments, but it was difficult to enter into contact with these individuals.

Open-ended in-depth interviews occurred within the facilities of the Hanover Park community clinic and the Hanover Park Day Hospital. The former is run by the Cape Town city government while the latter is run by the Western Cape provincial government. The TB clinic is run through the city community clinic while HIV-related services occur at the provincial Day Hospital.

The first author made daily visits to the TB clinic and HIV clinic to recruit and interview patients. She would introduce herself to the patient and if consent was received, take them to a private 
room to conduct the interview. Interviews were conducted primarily in English with discussions in Kaapse Taal (Cape Afrikaans, a local dialect) occurring in small amounts as well. Recruiting participants was often difficult. It was particularly difficult to identify patients from the TB clinic as appointments would be scattered throughout the day, and often not occurring on time. Recruiting young men was especially difficult. It was not possible to recruit active gang members as part of the study because they did not attend either facility within the six-week period.

Most interviews took between 30-45 minutes. Participants were informed about the study goals and the interview process. Participants were not hesitant to participate; in some cases, however, they appeared overly compliant and struggled to read the informed consent documents. This caused the first author some concern due to the voluntary nature of the interview. She explained the study and consent processes orally and reminded them they were free to not participate but most participants decided to move forward. Only one interview with an HIV/TB patient was declined because his mental capacity was limited, and he could only be spoken to with the help of his mother.

The interview guide was organised into three areas: 1 ) the effect of gang violence on the community and men's access to health facilities, 2 ) men's experiences in the HIV/TB care cascade, and 3) men's ideas about potential community-based interventions to improve men's access to care. The first author conducted a thematic analysis of collected data, including fieldnotes and interview transcripts, to identify core themes and sub-themes of interest. These themes were identified on an ongoing basis while collecting data and then further refined after the end of data collection. The first author discussed emerging findings with both co-authors throughout the analysis process.

This study was approved by the London School of Hygiene and Tropical Medicine and University of Cape Town's ethics committees (16986;802/2014). Informed consent was obtained from all interviewees. To preserve confidentiality, names of interviewees were not used in data storage and instead each participant was attributed an interview number.

\section{Results}

In Hanover Park, gang activity has a strong influence on residents' sexual practice and attitudes, especially among young men. Lines are drawn throughout the community based on gang affiliation, resulting in the movement of men being extremely limited. The reputation of the area for violence was of concern to many different people. As an illustration from a conversation with an Uber driver:

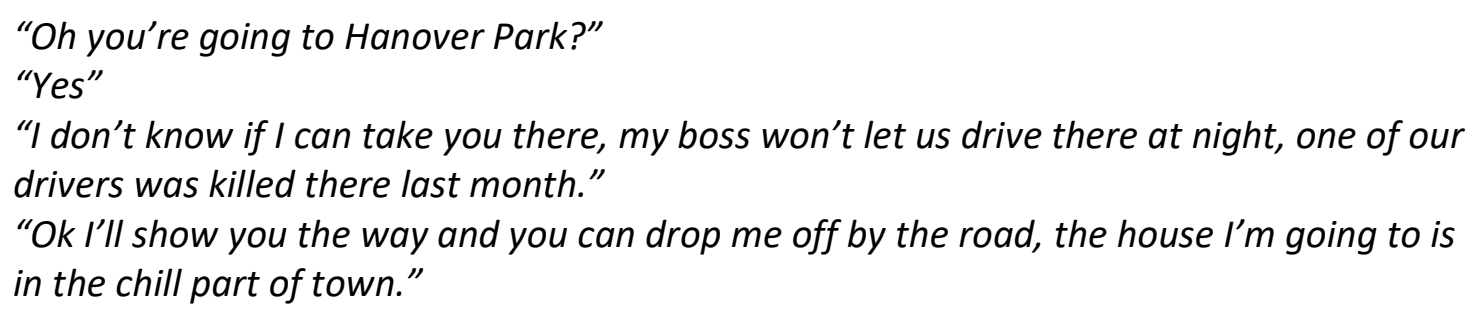


<hesitates>

"Seriously I'll show you the way, you'll drop me, and you'll turn back safely."

"Ok, but only because you let me pray before we started the journey."

However, going by minibus was a dramatically different experience. $\mathrm{My}^{1}$ morning and evening commutes include a vocal gaatjie (the fare collector), a gossiping taxi driver, and house beats blaring over the stereo. Whether full or with only a few straggling passengers, the ride was easy. Pulling into the neighbourhood, children were going to school, people were greeting each other in the streets, and groups of young people could be seen hanging out on street corners. Activity inhabits every part of the township.

At a moment's notice however, a gunshot could everything into disarray. The streets became empty, a thick silence hung in the air, and if you found yourself alone, the tension could become frighteningly palpable.

Gang culture is a dominant fact of life in Hanover Park. A scribbling of the word "Ghettos" on the wall will tell you you are in the Ghettos gang territory. An American flag outlined on another street corner tells you you have entered the domain of the Americans. As an "ordinary" person, gang culture may not mean much. One can still make a trip to the local shops and take a taxi ride out of town. Everyone, however, feels the weight of the violence tied to gang activity. Whether they have been robbed before, know of someone who was killed, or simply do not feel safe to leave their house, gangsterism weighs heavily on the minds of community members. According to residents, and in line with my own observations from the 2016-17 period up to now, the violence has escalated, more lives have been lost, and gunshots seem to tell the time of the day.

In many instances, violence is normalised.

It is early Sunday morning at our friend Jamila's house. The family is collected in the living room, chatting and sipping on coffee. As we laugh and gossip, we hear a single shot go off in the near distance. Our eyes open wide and l ask, 'was that down the road?'. Jamila's ${ }^{2}$ daughter's boyfriend peeks out the door of the flat 'No, it was in the court (apartment block) by us'. As he walks out, l ask, 'where are you going?'. He gives a small laugh "I'm going to see the body!"

In others, it can trigger incredible fear.

Joyce ${ }^{3}$ and I are walking to the taxi rank. We talk about the shooting that happened in the area behind her house only a few hours ago. I ask, 'Have you ever seen a shooting?' She laughs and pauses dramatically 'Yoh, Cathy, I was walking to my mom's once.... and then out of nowhere I see these guys running past me and one had a gun and shot for the other guy...... Yoh, Cathy I pissed my pants, like really, and I couldn't move. I was so scared'. 
Areas in Hanover Park can be divided into a few key gangs. Each section of the township is home to one, two, or even three gangs. Key groups are the Ghetto Kids (GK), Americans, Mongrels, Laughing Boys, Derwent Kids, and Dollar Kids. Under these gangs are sub-gangs that usually affiliate with the larger gangs. Also present are small, less significant gangs which are often dubbed "men's groups". The latter is mainly a forum for men to hang out and claim social status on the street or apartment block where they live. They do not necessarily participate in illicit activity.

Gangs can be involved in weapons smuggling, selling drugs, and fighting for control over territory. Shootings occur when gangsters try to gain new territory, settle a previous fight, or when gangsters step onto another gang's territory. These rules are not set in stone, however, as sometimes shootings appear senseless. Most residents of Hanover Park agree though that those who commit shootings are getting younger and younger.

A sunny day, I notice the streets are empty as I walk from Die Hanger [a microneighbourhood] back to the ARV clinic. Before I enter the hospital site, I see police cars in front. As I enter the clinic, a staff member exclaims 'Cathy were you walking just now?'

Yes, why?

They did shoot just now!

Later as I speak to another staff member, they tell me a Laughing Boy shot at a police car next to the hospital. The officer retaliated by shooting him twice in the head. The boy is 16 years old.

Constant shootings may be disorienting but are a norm in Hanover Park. Understanding how this violence is situated in the lives of men in Hanover Park is not always clear, but through discussion with community members, and interviews conducted the local TB and ARV clinic, some clear patterns emerged. Key finding related to the role of walking politics in access to care and younger men being the main demographic missing from care.

Walking politics: "They scared man"

My life is in danger, as soon as I go out that door, I never know what's going to happen --participant on the dangers of moving around Hanover Park as a man

The "walking politics" of Hanover Park are the rules that dictate mobility through gang territories. The standard rule is that a gangster from one gang should not enter the territory of another. Oftentimes, however, this extends to men who are not in gangs as well. Just entering a part of the township where you do not live can raise questions. 
P: Um....I can go to the Back Streets [micro-neighbourhood]...let me put it here like I said, I'm not that comfortable in that area, because of why, because the area that I come from and the area I'm going to is two different areas, even though I'm not.... gangster or whatever, you get marked by the area you come from. So if you move from like my area to the back streets you will have some trouble with the people or the guys.

\section{I: What kind of trouble?}

P: Um...firstly your face is not familiar so they will be harassing you, looking for something, looking for money from you, depends on the person. You can react or you can just walk away but if you react or walk away depending on what mood they $I, n$ you can get trouble.

I: How much trouble could you get in to?

P: You might lose your life.... you might lose your life...not you might, you will lose your life, if you from a different area, that's how it works here.

Walking politics more typically apply to men more than women. As a general sentiment, most people in Hanover Park feel unsafe walking to and fro because of the constant threat of gun violence. Trespassing and confrontations with gangsters, however, are associated more with men. The unfamiliar face of a man, or the familiar face of a rival gang member, notifies gang members in a particular area to potential suspicious or dangerous activity. An interloper could be a harmless stranger or could be someone sent to shoot at your gang.

The two healthcare facilities in Hanover Park are situated at the nexus of several gang territories. The Derwent Kids surround the community health clinic, the site of the TB centre, while the Mongrels and GKs surround the front and back of the day hospital, respectively. While these sites are not part of gang territory themselves, being surrounded by gangs entails the same association. Both facilities are located near the taxi rank which constitutes the busiest part of the township and is a hotspot for shooting. As a result, the day hospital has changed its working hours so that it now closes at $7 \mathrm{pm}$.

I: If you were a Mongrel could you come here [day hospital]?

P: Nope, nope, hellIIII no

I: Not even if you walk with a girl or an older lady?

$P$ : Nope--because this is a different territory

I: And an American, can they come here?

P: Yes because this is their territory 


\section{I: So if you were a Ghetto, you couldn't come here}

P: No. unless I had maybe..say for instance hey could you drive me there, I'm gonna jump out and maybe just run in. Just to be safe but if you have to walk then it's almost like a risk that you're taking

I: So unless you have a car there's no other way to get to the hospital?

P: So to say you just have to be there where you need to be in your territory

In the context of this patient, who was a non-gang member, mobility was possible but was almost a stealth mission. Traveling with a neighbourhood woman would ease his trip because it would divert suspicion. If the woman were not Coloured and/or older, his presence would attract even less concern. Unless he was be able to drive straight into the hospital parking lot, his chances of reaching the hospital by himself were slim, even as a non gang member.

Conversations and interviews confirmed that gang members cannot attend clinic sites affiliated with a rival gang's territory. This was not a surprise when speaking to the territorial divisions of the township. Most often shooting hotspots are areas where two gangs are in proximity to one another. Next to the hospital is a field across which the Mongrels and Americans face each other. To enter into the hospital and then reach the ARV clinic, one must pass through this field. Essentially, one must walk through potential crossfire to attend to one's health needs. For a gang member, this chance is dangerously amplified.

Now if you don't know what's your status---but you're not gonna come here also because it's for you like 'I'm not going to put my life in danger just to get tested, and then it's maybe negative'

Maybe gangsters who have HIV status and so onwards--other people who have that HIV status, it is [gang violence] the only reason they can't enter this site. Maybe they're from another gang you see. They also have HIV, that is why 'aagh, don't worry, I drink, I smoke, I live my life!' you know? Stuff like that. They don't get time to come here.

P: Yeah there's a few of my friends who don't walk anywhere. Or they just stay in that same area, cause they can't go out, because it's gang related.

I: What's the difference between you and them?

P: I don't wear the tattoos

I: Are any of them [HIV] positive?

P: A few of them, that I know of, yeah 


\section{Non-gangster struggles}

Understanding walking politics for gang members is relatively straightforward. With clear marking of affiliation, a man in this situation has limited mobility. This translates into restricted or even prohibited access to the local healthcare facilities in Hanover Park. For men who are not a part of gangs, the question of access is not as straightforward.

If a man who is not a part of a gang does not have a visible affiliation to a gang, he should in theory be allowed to pass through the various gang territories. The sheer fact that I was able to interview men from Hanover Park at these clinics is testament to this possibility. However, for some of these men, all of them under the age of 40 , this was not always the case.

\section{P: Even this side [neighbourhood] I walk but I get too much disturbances by those guys}

\section{I: What do you mean you get disturbances?}

P: For that gangsters when you are walking they ask you something like..they want to rob you or...so I don't know...I'm talking about this side of the clinic. Yesterday was my first time to come to this clinic. It was my first time to get TB. So they told me I'm supposed to walk [until] here for two weeks for this clinic. So I don't know what is going to happen with those gangsters. Even today I was walking that side and they started to talk to me.... Yoh! I'm worried by the talk they'll give me this side to come to ask...because they know you don't stay in this area so I don't know maybe one day they'll start more problems or whatever...

This participant was one of two men interviewed who lived in Hanover Park but did not grow up in the area. While they were aware of the surroundings of their area, they had much less knowledge of the politics of the Hanover Park gangs and as such, proved to be even more frightened by the climate of the township and their trips to the clinic. Both claimed that they rarely left the house due to safety concerns. When asked how they made it to the clinic, both responded that they were determined to complete their treatment and it was their top priority.

I was able to develop a better understanding of clinic attendance by asking participants how they were able to visit the site on that day, and in the past, and if they felt comfortable in making visits to the clinic in general. Of the younger participants, men who were between the ages of 24-34, there seemed to be a narrow window of opportunity that each one of them passed through to be able to make their visits. For some, this backdoor was straightforward. Driving to the clinic greatly reduced chances of being confronted by other men and, in general, is the safest way to move throughout Hanover Park. Another factor was the state of gang relations on a given day. One participant, an ex-gang member, noted that he was able to come to the clinic more easily because at the time of the interview, the Mongrels and Americans were at peace. This meant that he (and arguably active gang members as well) could make a trip to both facilities without a problem. Were this to change, however: 
I: So kind of thinking about the future you can keep on coming here [the clinic] and there won't be a problem?

P: Ummm...it depends <laughs> it depends on not having a gang war. If there is a gang war between the Americans and the Mongrels there's no way I can pass the Mongrels. If there is a gang war there is no way I can get past. They will either rob me or they will kill $m e$. The reason being, I'm from the Philly4. So it is not peace, so... I got free passage for now. But the moment they start killing and shooting one another, nobody's got free passage....then they take a risk

The day after this interview, shooting broke out between the above-mentioned gangs.

Other opportunities were created by drawing on support from friends and family. With the cases of the two participants who were the newest residents of Hanover Park, a brother or a friend who was familiar with the area or a known face to gang members, would walk them to the clinic, and this could reduce anxiety about trips to the clinic.

A key form of support, and in many cases, a free pass, was traveling with women. In Hanover Park, women are not the first target for shootings as women are not allowed to be gang members. As such, women are often able to move about, within their degree of comfort, without much of a problem. The first author herself walked back and forth from the clinic and hospital to an area of Hanover Park that she was familiar with and did not encounter many issues. When men travel with women, it lowers the suspicion around them and serves as a camouflage of sorts for men throughout the community.

I: Did you have problems walking here [day hospital] today?

P: No, because I walked with someone. I walked with a girl. So it's like [maybe they're boyfriend and girlfriend] you know It's almost like an undercover type of move. If I walk with her [his wife] my mind isn't on that [the threat of violence]....I mean it is on that... but I actually don't see any danger if I walk with her

For some though, a daily or monthly escort was not an option. Most often, patients who defaulted lived far from the clinic. Unfortunately, I was either not able to contact these individuals, or unable to interview them. Of the three identified ARV defaulters, two were not affiliated with gangs. I made contact with one, but he never came down to the clinic for the interview. The other, a young man in his early twenties, often told staff he was too scared to come to the clinic. Working not far from the taxi rank and day hospital, he had been off his ARVs for a couple of months but stressed that he did not feel comfortable taking the risk of coming down to the clinic. During the last week of fieldwork, he came to the clinic and was able to pick up his medication.

Many participants mentioned fear as constantly hanging over their shoulders, whether leaving their street, or when coming to the clinic. Other participants, who mentioned coming to the 
clinic was relatively easy for them, gently chided those who were afraid, saying those who did not come to the clinic were stupid. In the same vein, however, most participants recognised how complicated the situation was. While these select participants were successful in getting tested and on to treatment, they would also recognise that there were many men who simply fell through the cracks because of the oppressive fear of violence.

I don't have any friends....they're all dead

My cousin, they did shoot him in front of me...I was 21

Yeah...they're scared man. Last week man I lost my best friend......he was 35. He was going home, he was drinking, and those guys were coming through the court, they were going upstairs and he had a hoodie on his head, and they think he's a gangster and they shoot him

A few staff at the local clinic and hospital noted that men from the area rarely accessed services. While most mentioned gun violence as a deterrent, a few times it was mentioned that lines drawn by gang territory could serve as even more of an impediment. Staff were able to recall conversations in which patients or their partners informed them of the difficulty of reaching the clinic because of its location on a shooting hotspot:

I think there was this one guy also, and he lives actually close by! And then there's this woman that comes every time to fetch his meds and I was like Why? we need to take blood and she said no he can't come out of the house, I said is he in a gang? so she said No he's not in a gang, but if you just walk out then they assume you're in a gang. But I think he is in a gang, but she was also just protecting him.

In Hanover Park, a large number of men, especially young men, are involved in gangs. The activities tied to being a gang member often put these men in harm's way. Whether being the target of a shooting or missing the opportunity to get tested and treated for life-threatening disease, these men are in danger. During her time at the two clinics in focus, the first author never encountered an active gang member. With both of these clinics serving an area so entrenched in gang violence, it is disconcerting to imagine the scores of men unable to enter and remain in care. For those non-gang members who were successful in attending appointments, violence still played a role in how they organised their health matters, and for some it was a source of constant pressure.

What is even more troubling is that as the trends among gangs throughout the Cape Flats change, and gang members become younger and younger, the potential for these men to slip through the reach of health services is even stronger. Most men interviewed were older in age. With younger age groups being more at risk, especially for HIV, these findings demonstrate that an already key risk group remains out of reach. 
All participants understood the risks in place for gangsters, and most spoke negatively of the lifestyle. Feeling the pressure of violence on their shoulders, they could not imagine how men in gangs could cope with a lifestyle that often did not lead to a future. In a similar vein, these men empathised with gang members and their inability to engage with care. To them, why would someone care about their health if they are going to die anyway?

\section{Discussion}

Gang violence is a significant barrier to care for many men in Hanover Park. While some are able to negotiate around it, for men in gangs, or individuals closely associated with them, the chance to enter and remain in the HIV/TB care cascade is slim to none, leaving them essentially cut off from even considering pursuing their health needs.

The role of violence as a deterrent does not exist in isolation, however. As for most people, decision-making is multifaceted. That it was possible to obtain interviews at all demonstrates the narrow yet existing windows of opportunity men in Hanover Park have in seeking care. Understanding how the different contextual factors distinct to Hanover Park interact with each other when men engage with their health is vital in understanding how to lessen the strength of the barrier of violence to care.

Studies on violence and health rightly address the most affected populations of women and LGBT populations. To extend this work, it is critical that we broaden the gendered approach to violence and view it in the entirety of its spectrum (Fleming et al. 2015). Men are in large number affected by interpersonal violence, a concrete reality of daily life in a number of communities on the Cape Flats. This research demonstrates that in this instance, violence significantly challenges men in engaging in HIV/TB care.

In Hanover Park, men's lives are at risk. Shifting the conversation from the high rate of mortality from violence within the township to HIV and TB was not always natural for participants. Yet it remains important to emphasise to the men in Hanover Park and health programmers alike that these issues are not mutually exclusive. Using a syndemic health approach in the context of Hanover Park and much of the townships of the Cape Flats helps us better understand this community, the men that are a part of it, and the intertwined health and social problems they confront (Douglas-Vail, 2016).

Men in gangs have agency, yet agency is also severely limited by the environment they interact with. This study expands and refines the traditional body of literature on men in gangs by analysing a context in which men are not simply perpetrators of risk but also recipients. While it is important to catalogue the risk behaviours that men display in their performance of their gang membership, a more holistic picture is necessary, especially in attempts to better engage this group of men in their critical health needs (Ratele, 2014; Schmidt-Sane, 2018).

Men in gangs illustrate another case of the blind spot related to discussions of men and HIV and TB (Cornell et al., 2011; UNAIDS, 2017). The gap in men's engagement in these key health services is exacerbated in the distinct environment these men occupy. Men in gangs (or 
perhaps in organised crime at large) should be considered a key risk group in HIV and TB programming. This group should also be included in UNAIDS 2016-2021 Fast Track AIDS response strategy as a key population that should not be left behind in the AIDS response (UNAIDS Key Population Groups, 2020).

Gender and the social vulnerability produced by it are relational (Connell, 2012). Gendered power is relational. For racially and economically marginalised men, power is negotiated, reformulated and exercised in their gendered context (Messerschmidt \& Messner, 2018). Marginalised men also experience physical vulnerability, specifically in the context of gang violence, to the point that it not only discourages health engagement but essentially prevents it. For the HIV and TB cascades, which require consistent involvement, this vulnerability presents a grave challenge.

Men struggle with identities that emphasise the importance of strength and independence and their role as providers (Chikovore et al., 2015; Okoror et al., 2016; Siu et al., 2013). In the context of the Coloured communities in the Cape Flats, physical safety is yet another obstacle that obstructs men from seeking necessary prevention and treatment services. Yet this challenge also presents an opportunity for a coordinated, gender-resourceful intervention, one that would employ the abilities and vulnerabilities of different gender groups involved to mitigate the harms presented by the gendered context (Baral et al., 2014). Community-based interventions show promise in being particularly effective in improving uptake of testing and treatment for HIV/TB (Kibuule et al., 2019; Lippman et al., 2018; Sharma et al., 2017). Even more usefully, a gender-resourceful intervention would not only be community-based, but rather draw on resources embedded with communities themselves to be utilised towards combating harms nested within the inequities surrounding communities (Cassetti et al. 2020; La Peralta 2019)

This study demonstrates that women in Hanover Park, despite their overall lack of gender power, have some capabilities that men do not. They are not typically the same targets of gang violence that men are and are also more involved in community work - a resource of untapped potential when considering future interventions in this context. For many of the participants, a woman triggered their entrance in the care cascade. Thus, engaging men should not be an effort in isolation, and instead will need to rely on the key relationships that guide men to support and protect their health in the first place.

The sample in this study included men who were able to access the respective ARV and TB clinics in their community. Interviews and observations provided rich descriptions of the daily hazards that men faced in reaching their local health centres and the issues that prevented regular attendance. With the lack of regular attendance of younger clients, and the phenomenon of gang activity, this study argues that gang violence is a strong deterrent for men, especially young men, in accessing care. Further analysis however, focusing on patients who regularly default may further deepen our understanding of the issues at stake. 
Limitations of this study included the fact that the sample only included men who were able to access the respective ARV and TB clinics in their community. The majority of clients attending the clinics were over the age of 35 , which meant that the perspective of younger clients was missing. Our sample size of interviews was small but was complemented by ethnographic fieldwork.

\section{Conclusion}

Violence is woven into the fabric of daily life of Hanover Park; from the forced removals that brought scores of people far from their homes and thrust them upon a dusty tract of land, to the gang violence that plagues these same communities today, violence in Hanover Park is oppressive and profoundly alters the way people lead their lives. Tracing the grip of violence on men's ability to tend to their health needs is necessary to highlight violence's ability to act as a barrier to men's entrance and maintenance in HIV/TB care, as well as possibilities to mitigate its deleterious consequences.

Observations of Hanover Park, and conversations with people living with HIV/TB, demonstrate that violence is a strikingly significant deterrent to men in Hanover Park's access to HIV/TB care. This reality was even more stark for men involved in gangs, who as our results demonstrated, in most instances, were cut off from the clinic entirely. The task at hand, however, is getting men to overcome this hurdle.

This study adds to the growing research on men and HIV, and the nascent work on men and TB. It calls for more research on the gender disparity relating to access to care and on potential avenues to design programmes that respond to violence in a context-sensitive manner (Colvin, 2019; Horton et al., 2018). The findings of this study could be potentially extrapolated to the other Coloured townships of the Cape Flats and could prove useful if applied to other areas that are heavily affected by gang violence such as El Salvador, Brazil, and several cities within the United States.

\section{Notes}

1. Written from the perspective of first author

2. Pseudonym

3. Pseudonym

4. Name altered for publication

\section{Acknowledgements}

Our sincere gratitude to the amazing women at the Alcardo Andrews Foundation who were an incredible help in the execution of this project. This project was supported by the US National Institute of Mental Health and the South African Medical Research Council (SAMRC) (1R01 MH106600). The content of this paper is solely the responsibility of the authors and does not necessarily represent the official views of the US National Institutes of Health or the SAMRC.

\section{Disclosure Statement}

No potential conflict of interest was reported by the author(s). 


\section{Funding}

This work was supported by National Institutes of Mental Health; South African Medical Research Council [grant number R01 MH106600]

\section{ORCID}

Janet Seeley 0000-0002-0583-5272

Christopher Colvin 0000-0002-8930-7863

\section{References}

Adhikari, M. (2009). Burdened by race: Coloured identities in Southern Africa. Uct Press Cape Town.

Baral, S., Holland, C. E., Shannon, K., Logie, C., Semugoma, P., Sithole, B., Papworth, E., Drame, F., \& Beyrer, C. (2014). Enhancing benefits or increasing harms: Community responses for HIV among men who have sex with men, transgender women, female sex workers, and people who inject drugs. JAIDS Journal of Acquired Immune Deficiency Syndromes, 66, S319-S328.

Cassetti, V., Powell, K., Barnes, A., \& Sanders, T. (2020). A systematic scoping review of assetbased approaches to promote health in communities: development of a framework. Global Health Promotion, 27(3), pp. 15-23.

Chikovore, J., Hart, G., Kumwenda, M., Chipungu, G. A., \& Corbett, L. (2015). 'For a mere cough, men must just chew Conjex, gain strength, and continue working': The provider construction and tuberculosis care-seeking implications in Blantyre, Malawi. Global Health Action, 8(1), 26292.

Colvin, C. J. (2019). Strategies for engaging men in HIV services. The Lancet HIV.

Connell, R. (2012). Gender, health and theory: Conceptualizing the issue, in local and world perspective. Social Science \& Medicine, 74(11), 1675-1683.

Cornell, M., McIntyre, J., \& Myer, L. (2011). Men and antiretroviral therapy in Africa: Our blind spot. Tropical Medicine \& International Health, 16(7), 828-829.

Cornell, M., Horton, K., Colvin, C., Medina-Marino, A., \& Dovel, K. (2020). Perpetuating gender inequity through uneven reporting. The Lancet, 395(10232), p 1258. doi:10.1016/S01406736(20)30216-6 Retrieved from https://doi.org/10.1016/S0140-6736(20)30216-6

Crime Stats SA. (n.d.). Retrieved May 14, 2020, from https://www.crimestatssa.com/index.php

Douglas-Vail, M. (2016). Syndemics theory and its applications to HIV/AIDS public health interventions. International Journal of Medical Sociology and Anthropology, 4(1), 081090.

Fleming, P. J., DiClemente, R. J., \& Barrington, C. (2016). Masculinity and HIV: Dimensions of masculine norms that contribute to men's HIV-related sexual behaviors. AIDS and Behavior, 20(4), 788-798.

Fleming, P. J., Gruskin, S., Rojo, F., \& Dworkin, S. L. (2015). Men's violence against women and men are inter-related: recommendations for simultaneous intervention. Social Science \& Medicine, 146, pp. 249-256. 
Hensen, B., Taoka, S., Lewis, J. J., Weiss, H. A., \& Hargreaves, J. (2014). Systematic review of strategies to increase men's HIV-testing in sub-Saharan Africa. AIDS (London, England), 28(14), 2133.

Horton, K. C., MacPherson, P., Houben, R. M., White, R. G., \& Corbett, E. L. (2016). Sex differences in tuberculosis burden and notifications in low-and middle-income countries: A systematic review and meta-analysis. PLoS Medicine, 13(9).

Horton, K. C., White, R. G., \& Houben, R. M. (2018). Systematic neglect of men as a key population in tuberculosis. Tuberculosis (Edinburgh, Scotland).

Kanabus, A. (n.d.). TB in South Africa-The aim is elimination. TBFacts. Retrieved June 7, 2020, from https://tbfacts.org/tb-south-africa/

Kibuule, D., Rennie, T. W., Ruswa, N., Mavhunga, F., Thomas, A., Amutenya, R., Law, M. R., Günther, G., Ette, E., \& Godman, B. (2019). Effectiveness of community-based DOTS strategy on tuberculosis treatment success rates in Namibia. The International Journal of Tuberculosis and Lung Disease, 23(4), 441-449.

Lippman, S. A., Leddy, A. M., Neilands, T. B., Ahern, J., MacPhail, C., Wagner, R. G., Peacock, D., Twine, R., Goin, D. E., \& Gómez-Olivé, F. X. (2018). Village community mobilization is associated with reduced HIV incidence in young South African women participating in the HPTN 068 study cohort. Journal of the International AIDS Society, 21, e25182.

Logie, C. H., Lacombe-Duncan, A., Kenny, K. S., Levermore, K., Jones, N., Marshall, A., \& Newman, P. A. (2017). Associations between police harassment and HIV vulnerabilities among men who have sex with men and transgender women in Jamaica. Health and Human Rights, 19(2), 147.

Makanga, P. T., Schuurman, N., \& Randall, E. (2017). Community perceptions of risk factors for interpersonal violence in townships in Cape Town, South Africa: A focus group study. Global Public Health, 12(10), 1254-1268.

Makusha, T., van Rooyen, H., \& Cornell, M. (2020). Reframing the approach to heterosexual men in the HIV epidemic in sub-Saharan Africa. Journal of the International AIDS Society, 23(Suppl 2)

Mèdicine Sans Frontières (MSF) International (2019) La Peralta: a community organised by health / El Salvador https://www.msf.org/la-peralta-community-organised-health-elsalvador

Messerschmidt, J. W., \& Messner, M. A. (2018). Hegemonic, nonhegemonic, and new masculinities. Gender Reckonings: New Social Theory and Research, 35-56.

Mills, E. J., Beyrer, C., Birungi, J., \& Dybul, M. R. (2012). Engaging men in prevention and care for HIV/AIDS in Africa. PLoS Medicine, 9(2).

Okoror, T. A., Falade, C. O., Walker, E. M., Olorunlana, A., \& Anaele, A. (2016). Social context surrounding HIV diagnosis and construction of masculinity: A qualitative study of stigma experiences of heterosexual HIV positive men in southwest Nigeria. BMC Public Health, 16(1), 507.

Pillay-van Wyk, V., Msemburi, W., Laubscher, R., Dorrington, R. E., Groenewald, P., Glass, T., Nojilana, B., Joubert, J. D., Matzopoulos, R., \& Prinsloo, M. (2016). Mortality trends and differentials in South Africa from 1997 to 2012: Second National Burden of Disease Study. The Lancet Global Health, 4(9), e642-e653. 
Ratele, K. (2014). Currents against gender transformation of South African men: Relocating marginality to the centre of research and theory of masculinities. NORMA: International Journal for Masculinity Studies, 9(1), 30-44.

Salas-Wright, C. P., Olate, R., \& Vaughn, M. G. (2015). Substance use, violence, and HIV risk behavior in El Salvador and the United States: Cross-national profiles of the SAVA syndemic. Victims \& Offenders, 10(1), 95-116.

Salo, E. (2003). Negotiating Gender and Personhood in the New South Africa: Adolescent Women and Gangsters in Manenberg Township on the Cape Flats. European Journal of Cultural Studies, 6(3), 345-365. https://doi.org/10.1177/13675494030063005

Salo, E. (2006). Mans is ma soe: Ganging practices in Manenberg, South Africa and the ideologies of masculinity, gender and generational relations. States of Violence: Politics, Youth, and Memory in Contemporary Africa, 148-178.

Schmidt-Sane, M. M. (2018). Community vulnerability and stratified risk: Hegemonic masculinity, socioeconomic status, and HIV/AIDS in a sex work community in Kampala, Uganda. Global Public Health, 13(11), 1713-1724.

Sharma, M., Barnabas, R. V., \& Celum, C. (2017). Community-based strategies to strengthen men's engagement in the HIV care cascade in sub-Saharan Africa. PLoS Medicine, 14(4).

Shisana, O., Rehle, T., Simbayi, L. C., Zuma, K., Jooste, S., Zungu, N., Labadarios, D., \& Onoya, D. (2014). South African national HIV prevalence, incidence and behaviour survey, 2012.

Siu, G. E., Seeley, J., \& Wight, D. (2013). Dividuality, masculine respectability and reputation: How masculinity affects men's uptake of HIV treatment in rural eastern Uganda. Social Science \& Medicine, 89, 45-52.

Siu, G. E., Wight, D., \& Seeley, J. A. (2014). Masculinity, social context and HIV testing: An ethnographic study of men in Busia district, rural eastern Uganda. BMC Public Health, 14(1), 1-11.

UNAIDS (2020) Key population groups, including gay men and other men who have sex with men, sex workers, transgender people and people who inject drugs. https://www.unaids.org/en/topic/key-populations

UNAIDS (2017) Addressing a blind spot in response to HIV - reaching out to men and boys https://www.unaids.org/en/resources/documents/2017/blind_spot

Voisin, D. R., Jenkins, E. J., \& Takahashi, L. (2011). Toward a conceptual model linking community violence exposure to HIV-related risk behaviors among adolescents: Directions for research. Journal of Adolescent Health, 49(3), 230-236.

Walsh, S., \& Mitchell, C. (2006). 'I'm too young to die': HIV, masculinity, danger and desire in urban South Africa. Gender \& Development, 14(1), 57-68. 